\title{
The Relationship Between the Fit of Employee Value and Company Culture and Performance
}

\section{Lu Xiu}

Department of Economics and Management, North China Electric Power University, Baoding, China

\section{Email address:}

luxiu2016@126.com

\section{To cite this article:}

Lu Xiu. The Relationship Between the Fit of Employee Value and Company Culture and Performance. Science Innovation. Vol. 5, No. 3, 2017, pp. 180-186. doi: 10.11648/j.si.20170503.20

Received: February 14, 2017; Accepted: May 2, 2017; Published: May 4, 2017

\begin{abstract}
As the soul of the enterprise, corporate culture provides its development inexhaustible power. However, with the new generation gradually into the workplace, they as a part of the workplace can not be ignored. The main body of the workplace identity of the corporate culture directly affect the individual and the long-term development of enterprises.From the existing research found that most scholars had a lot of research for the relationship between the three of employees values,corporate and performance.But the relationship between employees identity and performance in different age groups is still a black box.This paper selected the employees born in the 1970s, 1980s and 1990s, and used the SPSS statistical software to test the collected data through the use of test questionnaires. The purpose was to study the relationship between the individual values of different age employees and the different types of corporate culture; the degree of fit between the two and the significant degree of performance.
\end{abstract}

Keywords: Personal Values, Corporate Culture, Performance, Correlation Analysis, Regression Analysis

\section{员工价值观一企业文化契合度与绩效关系研究}

\section{卢绣}

经济管理系, 华北电力大学, 保定, 中国

\section{邮箱}

luxiu2016@126. com

摘要: 企业文化作为企业的灵魂对其发展提供着不竭的动力。然而, 随着新生代逐渐进入职场, 他们成为了职场中不 可忽视的一部分。职场主体对所在企业文化的认同与否都会直接影响着个人以及企业的长期发展。从现有的研究中发 现大部分学者对于某一特定年龄段员工的价值观、企业文化以及绩效三者之间的关系进行了大量研究，但是不同年龄 段员工对企业文化的认同与绩效之间的关系这方面还是一个黑箱。本文选取七十年代、八十年代以及九十年代出生的 员工为代表, 通过采用测试问卷的方式运用SPSS统计软件对采集到的数据进行过实证分析, 从而研究不同年龄段员工 的个人价值观与不同企业文化类型的契合度；两者之间的契合度与绩效之间的显著程度两个问题。

关键词：个人价值观，企业文化，绩效，相关性分析，回归分析 


\section{1. 引言}

企业文化作为企业竞争中的软实力具有很强的导向 作用, 它就像一根无形的指挥棒, 使得员工可以按照企业 的要求来规范自己的行为。企业文化只有通过价值观、仪 式、行为规范等形式落到管理中, 获得不同年龄段的员工 的高度认同才能保证企业拥有持久的生命力。受社会环境、 家庭环境、教育程度等影响，不同年龄段的员工对同一企 业文化的认同度不同, 会影响员工个人以及组织的绩效。 研究不同年龄段员工价值观一一企业文化的契合度与绩 效关系既可以拓展企业文化的深度促进企业文化的合理 化建设, 又能够为制定合理的人力资源政策提供合理的依 据, 为企业的发展提供不竭动力。

\section{2. 文献综述}

\section{1. 企业文化相关研究}

1981年美国的管理界对于企业文化进行了深刻的研 究从而推出来一系列有关企业文化的专著, 这就标志着企 业文化理论的正式提出。对于企业文化的概念, 大量的学 者专家从因素构成角度、价值观与行为角度以及经济角度 进行了详细的阐述; 对于企业文化的构成因素方面, 以余 世维（2005） [1]、丁政（2007）[2]为代表的两层观; 以 沙因（1985）［3]和陈传明（2005）[4]为代表的三层观以 及以陈丽琳（2007）[5]、秦德智（2013）[6]为代表的四 层观尤为突出, 本文选取秦德智的观点, 把企业文化分为 精神文化、制度文化、行为文化以及物质文化; 对于企业 文化的测量研究是良好掌握企业文化的核心部分, 在大量 的研究中越来越多的学者注重定量研究, 如: 卡梅伦的 OCAI量表; Denison的OCQ量表; Chatman的OCP量表。

表1 企业文化。

\begin{tabular}{|c|c|c|c|}
\hline 类型 因素 & 作者 & 观点 & 观点界定 \\
\hline \multirow{4}{*}{ 概念 } & Hofstede & 特定成分 & \multirow{8}{*}{$\begin{array}{l}\text { 企业文化是由价值观、仪式、英雄人物等要素构成 } \\
\text { 企业文化是在生产经营过程中所形成的具有独自特色的精神理念 } \\
\text { 企业文化是影响员工态度与行为, 协调与激励员工产生更高层次的绩效 } \\
\text { 显性层是指一般文化; 隐性层是指特殊文化 } \\
\text { 个体层面是指保健因素与激励因素; 群体层面是指群体的过程结果导向等; } \\
\text { 组织层面是指社会核心价值观层 } \\
\text { 精神文化指企业精神、哲学以及道德等; 制度文化指组织机构、企业民主等; } \\
\text { 行为文化指企业素质、风格以及影响; 物质文化指企业形象、环境以及目标 } \\
\text { 结果导向型文化是指企业文化完全服务于企业的利益; 员工导向型文化指以员 } \\
\text { 工的需求、利益为前提 } \\
\text { 硬汉型文化指鼓励内部竞争、鼓励冒险; 享受型文化指工作与娱乐并重, 奢注 } \\
\text { 型文化指在周密分析基础上孤注一郑; 过程型文化着眼于如何做, 基本没有工 } \\
\text { 作的反馈。员工的工作很难量 }\end{array}$} \\
\hline & Denison & 价值观 & \\
\hline & $0 \operatorname{Reilly}^{[7]}$ & 绩效 & \\
\hline & 余世维 & 显性层, 隐性层 & \\
\hline \multirow[t]{2}{*}{ 构成因素 } & 陈传明 & & \\
\hline & 秦德智 & $\begin{array}{l}\text { 精神文化, 制度文化 } \\
\text { 行为文化, 物质文化 }\end{array}$ & \\
\hline \multirow[b]{2}{*}{ 分类 } & 张玮 & 结果导向文化, 员工导向文化 & \\
\hline & 迪尔, 肯尼迪 & $\begin{array}{l}\text { 硬汉型文化, 享受型文化 } \\
\text { 奢注型文化, 过程型文化 }\end{array}$ & \\
\hline
\end{tabular}

\section{2. 员工价值观与企业文化契合度相关研究}

在西方组织行为学中很关注员工与企业之间的关系 研究。1994年德国的学者马丁与波尔纳提出 “渐进式管理” 促进了西方管理学的研究, 它指出企业文化应该打破传统 的静态的思维约束, 在企业发展的不同阶段应该采用动态 的渐进式的管理方式, 在企业活动中需要注重员工与企业 之间的交流。现有的研究认为员工个人价值观与企业文化
的契合度研究不仅对于员工个人而且对于组织来说都有 很深远的战略意义。尹静 (2013) 对个人的价值观与企业 文化的契合度进行了假设和度量, 指出企业文化落地过是 个人与企业间的磨合协调的过程, 企业文化受到员工个人 特征中多重作用的影响 [8]。

从实际来说, 现实生活中越来越多的企业开始重视企 业文化的建设上与员工的个人价值观相融合。

表2 员工个人价值与企业文化契合案例。

\begin{tabular}{|c|c|c|c|}
\hline 企业 维度 & 研究角度 & 理念 & 相关实例界定 \\
\hline 瑞典宜, 家家居 & 人本主义 & 员工比上帝更重要, 把问题转化成机遇 & \multirow{4}{*}{$\begin{array}{l}\text { GillisLundgren的Tore抽屉柜 } \\
\text { NielsCammelgaard的莫门特沙发 } \\
\text { 全体员工为文业文化的主体; 注重员工的心理需求 } \\
\text { 个性化的职业生涯规划策略; 技术、业务、管理系 } \\
\text { 统三大晋升途径 } \\
\text { 同行业中离职率最低; 员工薪资在业界的前25\%; } \\
\text { “咖啡豆股票” 机制 }\end{array}$} \\
\hline 联想 & 亲情文化 & 服务客户、精准求实, 诚信共享、创业创新 & \\
\hline 中兴通讯 & 相互尊重 & 保障个人良好的发展空间; 提供极具竞争力的薪资待遇 & \\
\hline 星巴克 & 平等快乐 & 领导把自己视为普通一员; 将员工称为 “合伙人” & \\
\hline
\end{tabular}




\section{3. 绩效相关研究}

绩效理论早在1990年已经受到了人力资源领域研究者的重视。对于绩效理论的学说大致分为个体层次、以及组织 层次。

表3 绩效指标。

\begin{tabular}{lll}
\hline 作者 & 指标 & 绩效指标 \\
\hline SeashoreEphaim[9] & 营业额、生产力、生产成本、市场渗透力、人力成长、营业组合、新成员生产力、成员年轻度等 \\
Campbe11[10] & 生产力、整体绩效、员工满意度、流动率、投资回报率等 \\
MaduKaccob & 短期绩效、长期绩效、生产力、成本' 利润、竞争力、市场占有率等 \\
\hline
\end{tabular}

\section{3. 研究分析}

\section{1. 不同年龄段员工特质以及价值观研究}

\section{1. 1. 不同年龄段员工特质以及价值观分析}

1970年至1979年时期出生人的这一代人的成长经历了 改革开放以及中国社会体制转型。这也是新个人主义和新 物质主义形成以及小学与中学甚至大学时期经历中国大学 教育最黄金的阶段。这代人受传统文化的影响, 大多数思 想比较保守, 能吃苦耐劳, 做事情有计划有条理, 在道德 上也有自己的标准, 但是整体来讲缺乏个性与创新。例如 在做企业培训中一般这些员工只是很认真被动地接受, 相 比1980年至2000年出生的人来讲没有太多的思想碰撞。

据《中国统计年鉴》数据显示我国在1980年至 1990 年出生的人约为 2 亿人。“这代人一半是火焰, 一半是海 水, 他们就是生活在冰与海之间的职业人”, 这句话真正 体现出了这代人的整体特征。从他们生活的社会大背景来
看, 在社会变革最快的社会初期, 计划生育政策、九年义 务教育、大学扩招以及通货膨胀物价飞涨使得他们具有敏 捷的思维、追求个性以及成就动机大于现实的特点。但是 “青鸟综合证” 也是在这一年龄段人员职场中常见的一 种现象, 即总是感觉对自己的工作不满意, 但是又找不到 合适的岗位以及机会, 因此在职场中跳槽现象频繁。

1990年至2000年出生的人员是伴随着互联网发展起来 的。在这种大环境下他们有着对新事物的喜爱与追求, 坚持 一种平等的互联网精神, 沟通方式趋向于直言不讳 [11]。80 年代的人员基础上更加注重个性的张扬而不是共性的趋同, 在职场上更加注重平等的交流而不是层级的控制。一方面他 们会对自己认可的工作坚持到底, 一方面又坚持工作只是生 活的一部分, 对工作的要求首先是快乐然后是成长。

\section{1.2. 量表设计}

在个人价值观量表设定中借鉴了Meyer等的量表，分 为了三个维度: 舒适和安全、能力和成长、地位和独立。

表4 个人价值观量表。

\begin{tabular}{|c|c|c|c|}
\hline 年龄层次 因素 & 70年代员工服从组织 & $\Rightarrow 80$ 年代员工青鸟组织 & $\square 90$ 年代员工海豚组织 \\
\hline 舒适和安全 & $\begin{array}{l}\text { 安全感建立在被人的认可上; 工作踏 } \\
\text { 实但创新能力不强; 一般为中高层管 } \\
\text { 理者; 为了家庭而努力奋斗 }\end{array}$ & 8 & \\
\hline 能力和成长 & & $\begin{array}{l}\text { 安全感较差; 看中自我追求独立; 成就动机大 } \\
\text { 于现实; 理想主义严重; 追求自我能力的提升 }\end{array}$ & 8 \\
\hline 地位和独立 & & & $\begin{array}{l}\text { 对工作要求一是快乐二是成长; 勇于 } \\
\text { 追求刺激与挑战; 享受生活, 具有独 } \\
\text { 立的人格与自信。 }\end{array}$ \\
\hline
\end{tabular}

\section{2. 企业文化}

\subsection{1. 企业文化的特性}

企业文化具有独特性与代表性, 每个企业的企业文化 都受其独特的成长过程、发展阶段、成长环境以及特殊的 员工共同影响, 并且植根于员工的价值观、行为规范中。 企业文化具有刚性的特征, 陈传明（2005）指出企业文化 的刚性特征包含四个方面即：难以改变性、惰性、抗性以 及边际收益呈 “倒U” 型分布。受企业的成长阶段的影响, 其企业文化呈现不同的特性。在成长阶段, 企业由于管理 的强度不够、技术以及各方面能力的弱小很容易被其他强 大公司的企业文化吞噬。于是企业管理者会特别关注内部
管理，保持企业能够长期稳定发展。成熟阶段，由于企业 对各种长期战略目标的重视使得企业文化不断走向情性, 使得企业文化的刚性化达到最高点。

\subsection{2. 企业文化的测量}

企业文化的测量源于竞值架构理论, 但是竞值架构理 论是从有效组织衡量指标模型的研究中得到的。对于企业 文化的分类, 本文选取了迪尔与肯尼迪的四种分类形式: 硬汉文化、奢注型文化、过程型文化以及享受型文化并且 结合了Quinn和Rohrbaugh (1983) 对于组织效能衡量指标 的研究对企业文化进行测量。

其中横坐标的两个维度中内部性是指重视企业内部 员工的发展, 外部性是指过多重视企业本身在行业内部的 
发展; 纵坐标两个维度中稳定与控制是指注重企业内部的 稳定性强调对管理的控制力, 变革与弹性是指注重企业自 身的变革以及弹性发展模式。

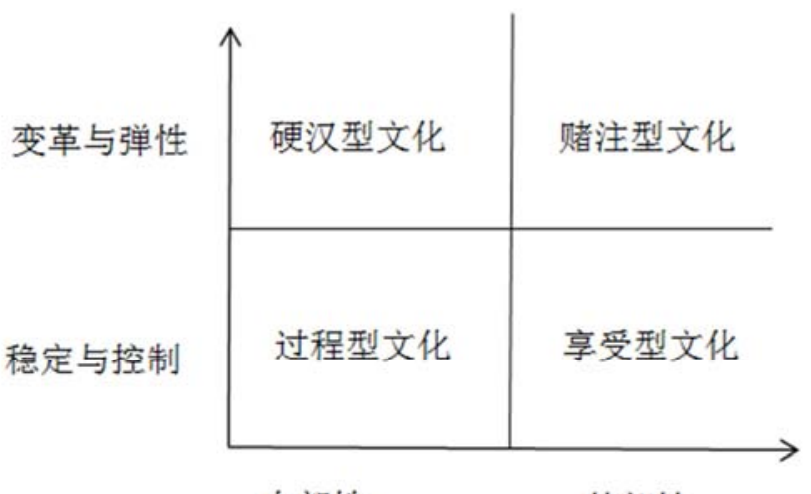

内部性
图1 企业文化的分类。

\section{3. 绩效}

从实践中可以看出, 绩效管理在提高员工组织绩效方 面起着关键作用, 为此企业将绩效管理放到了重要的位置 [12]。企业绩效作为衡量企业经营成果的标准它的高低直 接反映一段时间内企业战略是否落实以及目标是否实现。 由于关于企业绩效具有动态性、多维度、多层次的特点, 对企业绩效的评判标准不唯一。

从各种相关文献中可知, 依据不同对企业绩效的划分层 次不同。从划分对象上来看, 可以把企业绩效划分成组织绩 效、部门绩效以及个人绩效; 组成因素不同可分为战略制定、 非人力资源、知识等; 系统不同划分为财务、顾客满意度、 内部流程以及学习与成长四个部分, 也是目前很多企业中所 采用的平衡计分卡。本文把企业绩效指标分为两大类财务类 指标和非财务类指标, 由于财务类型的指标在现实员工调查 问卷中很难得出因此在设定财务类指标时注重企业的整体 竞争力、组织效率、在行业中的发展空间等。在非财务指标 的设定上选取在不同员工对企业文化不同认同度情况下的 员工工作满意度、离职倾向以及学习与成长空间。

\section{4. 研究设计}

\section{1. 研究变量的描述性分析}

本次的调查问卷对象分别为来自保定、石家庄、北京 等地的七十年代、八十年代以及九十年代的在职员工共 123 人。本文通过对有效的调查问卷进行描述性分析。
表5 各类变量的统计。

\begin{tabular}{|c|c|c|c|}
\hline 变量 & 类别 & 频数 & 比率 (\%) \\
\hline \multirow{2}{*}{ 性别 } & 男 & 63 & $51.22 \%$ \\
\hline & 女 & 60 & $48.78 \%$ \\
\hline \multirow{3}{*}{ 年龄段 } & 70年代 & 23 & $18.7 \%$ \\
\hline & 80年代 & 39 & $31.71 \%$ \\
\hline & 90年代 & 61 & $49.69 \%$ \\
\hline \multirow{3}{*}{ 职务 } & 普通员工 & 73 & $59.34 \%$ \\
\hline & 中层管理者 & 36 & $29.27 \%$ \\
\hline & 高层领导 & 14 & 11. $39 \%$ \\
\hline \multirow{4}{*}{ 最高学历 } & 高中/中专及以下 & 12 & $9.76 \%$ \\
\hline & 大专 & 25 & $20.33 \%$ \\
\hline & 本科 & 73 & $59.35 \%$ \\
\hline & 硕士以及以上 & 13 & $10.56 \%$ \\
\hline \multirow{3}{*}{ 工作年限 } & 1年以下 & 52 & $42.27 \%$ \\
\hline & 1-5年 & 48 & $39.02 \%$ \\
\hline & 5年以上 & 23 & 18. $71 \%$ \\
\hline \multirow{3}{*}{ 企业性质 } & 国有企业 & 35 & $28.46 \%$ \\
\hline & 民营企业 & 70 & $56.91 \%$ \\
\hline & 外资企业 & 18 & $14.63 \%$ \\
\hline
\end{tabular}

在本次调查问卷中可以看出男女调查人数相差 3 人; 年龄段中 90 年代的员工相对较多; 学历分布上大多是本科 学历; 大部分为普通员工, 工作年限在一年以下以及 $1-5$ 年中较多; 工作的企业为民营企业最多。

表6 研究性变量的描述性统计分析。

\begin{tabular}{lllll}
\hline & 指标数量 & 极大值 & 均值 & 标准差 \\
\hline 个人价值观 & 9 & 5 & 3.7056 & 0.8298 \\
企业文化 & 19 & 5 & 3.6173 & 0.6436 \\
企业绩效 & 13 & 5 & 3.4213 & 0.5832 \\
\hline
\end{tabular}

对所研究的变量进行描述性统计分析可以看出数据 的集中程度以及离散情况。

\section{2. 信度与效度分析}

表7 信度分析。

\begin{tabular}{llll}
\hline 维度 & 项数 & $\begin{array}{l}\text { Cronbach' sAlp } \\
\text { ha }\end{array}$ & $\begin{array}{l}\text { 基于标准化项的 } \\
\text { CronbachsAlpha }\end{array}$ \\
\hline 个人价值观 & 9 & 747 & 746 \\
企业文化 & 19 & 927 & 931 \\
绩效 & 13 & 885 & 890 \\
\hline
\end{tabular}

本文通过采用Cronbach' s 系数作为评判的标准, 一般来 讲系数在 0.9 以上表示可信程度越高; 0.8 以上可行程度可以 接受； 0.7 以上通过修改之后任然具有价值。本文选择的三 个维度其可信度都在 0.7 以上表示其调查具有研究价值。

表8 效度分析。

\begin{tabular}{llll}
\hline 变量 & KM0 与Bartlett球形检验 & & \\
\hline & 取样足够度的Kaiser-Meyer-01kin度量 & 628 \\
个人价值观 & & 近似卡方 & 1238.770 \\
& Bartlett的球形检验 & df & 45 \\
& & Sig. & 000 \\
企业文化 & 取样足够度的Kaiser-Meyer-01kin度量 & 近似卡方 & 790 \\
& Bartlett的球形检验 & df & 2131.2 \\
\hline
\end{tabular}




\begin{tabular}{|c|c|c|c|}
\hline 变量 & KM0与Bartlett球形检验 & & \\
\hline \multirow{5}{*}{ 绩效 } & & Sig. & 000 \\
\hline & 取样足够度的Kaiser-Meyer-01kin度量 & & 762 \\
\hline & & 近似卡方 & 1891.03 \\
\hline & Bartlett的球形度检验 & $\mathrm{df}$ & 96 \\
\hline & & Sig. & 000 \\
\hline
\end{tabular}

KMO一般用于研究变量之间的偏相关性, 当KMO大于 0.9 时为最佳; 当KMO 小于 0.5 时不适合做因子分析。 Bartlett球形检验中如果值越大并且相关概率小于 0.05
则变量之间的相关性就越强。以上可以看出三个变量的 $\mathrm{KMO}$ 都在 0.6 以上可以做因子分析。

\section{3. 相关分析}

表9 不同年龄段员工与不同类型文化的相关性分析。

\begin{tabular}{llllll}
\hline & & 硬汉型文化 & 奢注型文化 & 享受型文化 & 过程型文化 \\
\hline \multirow{3}{*}{ 七十年代员工个人价值观 } & Pearson相关性 & $548^{* *}$ & $101^{*}$ & $289^{*}$ & $699^{* *}$ \\
& 显著性 (双侧) & 004 & 001 & 019 & 110 \\
& $\mathrm{~N}$ & 23 & 23 & 23 & 23 \\
八十年代员工个人价值观 & Pearson相关性 & $641^{* *}$ & $740^{* * *}$ & 000 & $216^{* *}$ \\
& 显著性 (双侧) & 000 & 000 & 39 & 000 \\
& $\mathrm{~N}$ & 39 & 39 & $820^{* * *}$ & $240^{* * *}$ \\
九十年代员工个人价值观 & Pearson相关性 & $150^{*}$ & $761^{* *}$ & 000 & 000 \\
& $\mathrm{~N}$ & 000 & 000 & 61 & 61 \\
\hline
\end{tabular}

**. 在. 01 水平 (双侧) 上显著相关。

$*$. 在 0.05 水平 (双侧) 上显著相关。

从表 9 中可以看出在 0.05 水平上均显示显著正相关, 其中七十年代员工个人价值观与硬汉型文化以及过程型 文化的联系强度较强契合度较高, 分别为 0.548 以及 0.699 , 说明七十年代员工个人价值观更倾向于一种内部稳定、按 部就班一切按规章制度办事的企业文化。八十年代员工的 个人价值观与硬汉型以及奢注型文化联系强度较强契合 度较高, 分别为 0.641 与 0.740 , 这说明以八十年代员工的
整体价值观来看更倾向于一种注重竞争以及绩效, 敢于创 新有挑战性的企业文化。九十年代员工的个人价值观与奢 注型以及享受型的企业文化联系强度较强契合度较高, 分 别为 0.761 与 0.820 , 说明以九十年代员工的整体价值观来 讲更适合于一种有创新有挑战有竞争但是又具有人性化 的企业文化, 在这种文化下企业与员工是一种合作关系而 并不是一种压榨与被压榨的关系。

\section{4. 回归分析}

\section{4.1. 个人价值观、企业文化与绩效的回归分析}

表10 个人价值观、企业文化、绩效回归分析结果。

\begin{tabular}{|c|c|c|c|c|c|c|c|c|c|c|}
\hline \multirow{2}{*}{ 模型 } & \multirow{2}{*}{$\mathrm{R}$} & \multirow{2}{*}{ R方 } & \multirow{2}{*}{ 调整R方 } & \multirow{2}{*}{ 标准估计误差 } & \multicolumn{5}{|c|}{ 更改统计量 } & \multirow{2}{*}{ DW } \\
\hline & & & & & R方更改 & F更改 & $\mathrm{df} 1$ & $\mathrm{df} 2$ & Sig. F更改 & \\
\hline 1 & $776^{\mathrm{a}}$ & 602 & 589 & 5.54187 & 602 & 47.567 & 2 & 63 & 000 & 1.877 \\
\hline
\end{tabular}

a. 预测变量: (常量), 企业文化, 个人价值观。

表11 系数。

\begin{tabular}{|c|c|c|c|c|c|c|c|c|c|c|}
\hline \multirow{2}{*}{ 模型 } & & \multicolumn{2}{|c|}{ 非标准化系数 } & 标准系数 & \multirow[b]{2}{*}{$t$} & \multirow{2}{*}{ Sig. } & \multicolumn{2}{|c|}{ B的 $95.0 \%$ 置信区间 } & \multicolumn{2}{|c|}{ 共线性统计量 } \\
\hline & & $\mathrm{B}$ & 标准误差 & 试用版 & & & 下限 & 上限 & 容差 & VIF \\
\hline \multirow{3}{*}{1} & （常量） & 11.814 & 5.317 & & 2.222 & 030 & 1.190 & 22.439 & & \\
\hline & 个人价值观 & -.212 & 153 & -.119 & -1.386 & 171 & -.519 & 094 & 860 & 1. 163 \\
\hline & 企业文化 & 551 & 058 & 812 & 9.472 & 000 & 434 & 667 & 860 & 1.163 \\
\hline
\end{tabular}

a. 因变量: 绩效。

从表 10 与表 11 中可以看出 $R$ 方为 0.602 , 调整后的 $R$ 方为 0.589 , 均大于 0.5 , 可以看出变量之间的线性关系 较强, 样本数据的拟合优度较高; 回归的F值可以看出
回归系数 $0.000<0.001$, 则有显著性; DW为 1.877 接近于 2 , 则不存在自相关; VIF值均小于 10 , 则也不存在多重线 性问题。 


\section{4. 2. 不同年龄段员工的个人价值观一一企业文化的契合度与绩效的回归分析}

表12 七十年代员工价值观一一企业文化契合度与绩效回归分析结果。

\begin{tabular}{|c|c|c|c|c|c|c|c|c|c|c|}
\hline \multirow{2}{*}{ 模型 } & \multirow{2}{*}{$\mathrm{R}$} & \multirow{2}{*}{ R方 } & \multirow{2}{*}{ 调整R方 } & \multirow{2}{*}{ 标准估计的误差 } & \multicolumn{5}{|c|}{ 更改统计量 } & \multirow[b]{2}{*}{ - DW } \\
\hline & & & & & R方更改 & F更改 & $\mathrm{df} 1$ & df2 & Sig. F更改 & \\
\hline 1 & $751^{\mathrm{a}}$ & 564 & 543 & 5.84613 & 564 & 26.701 & 3 & 62 & 000 & 1.779 \\
\hline
\end{tabular}

a. 预测变量: (常量), 过程型文化, 七十年代员工个人价值观, 硬汉型文化。

b. 因变量: 绩效。

表 13 系数。

\begin{tabular}{|c|c|c|c|c|c|c|c|c|c|c|}
\hline \multirow{2}{*}{ 模型 } & & \multicolumn{2}{|c|}{ 非标准化系数 } & \multirow{2}{*}{$\begin{array}{l}\text { 标准系数 } \\
\text { 试用版 }\end{array}$} & \multirow[b]{2}{*}{$t$} & \multirow{2}{*}{ Sig. } & \multicolumn{2}{|c|}{ B的95.0\%置信区间 } & \multicolumn{2}{|c|}{ 共线性统计量 } \\
\hline & & B & 标准误差 & & & & 下限 & 上限 & 容差 & VIF \\
\hline \multirow{4}{*}{1} & （常量） & 9.104 & 5.199 & & 1.751 & 085 & -1.288 & 19.496 & & \\
\hline & 七十年代员工个人价值观 & 037 & 414 & 008 & 090 & 928 & -.790 & 865 & 879 & 1. 138 \\
\hline & 硬汉型文化 & 712 & 241 & 313 & 2. 961 & 004 & 231 & 1. 193 & 631 & 1.584 \\
\hline & 过程型文化 & 1.277 & 244 & 528 & 5.229 & 000 & 789 & 1.765 & 690 & 1. 449 \\
\hline
\end{tabular}

a. 因变量:绩效。

从表 12 和13中可以看出在七十年代员工价值观一企业 文化契合度与绩效回归分析中, $R$ 方为 0.564 , 调整后的 $R$ 方为 0.543 , 均大于 0.5 , 可以看出变量之间的线性关系较
强, 样本数据的拟合优度较高; 回归的 $\mathrm{F}$ 值可以看出回归系 数 $0.000<0.001$, 则有显著性; $D W$ 为 1.779 接近于 2 , 则不存 在自相关; VIF值均小于 10 , 则也不存在多重线性问题。

表14八十年代员工价值观一一企业文化契合度与绩效回归分析结果。

\begin{tabular}{|c|c|c|c|c|c|c|c|c|c|c|}
\hline \multirow{2}{*}{ 模型 } & \multirow{2}{*}{$\mathrm{R}$} & \multirow{2}{*}{ R方 } & \multirow{2}{*}{ 调整R方 } & \multirow{2}{*}{ 标准估计的误差 } & \multicolumn{5}{|c|}{ 更改统计量 } & \multirow{2}{*}{ - Durbin-Watson } \\
\hline & & & & & R方更改 & F更改 & $\mathrm{df} 1$ & $\mathrm{df2}$ & Sig. F更改 & \\
\hline 1 & $678^{a}$ & 546 & 534 & 6.50263 & 460 & 17.619 & 3 & 62 & 000 & 1.931 \\
\hline
\end{tabular}

a. 预测变量: (常量), 奢注型文化, 八十年代员工个人价值观, 硬汉型文化。

b. 因变量: 绩效。

表15 系数。

\begin{tabular}{|c|c|c|c|c|c|c|c|c|c|c|}
\hline \multirow{2}{*}{ 模型 } & & \multicolumn{2}{|c|}{ 非标准化系数 } & \multirow{2}{*}{$\begin{array}{l}\text { 标准系数 } \\
\text { 试用版 }\end{array}$} & \multirow[b]{2}{*}{$\mathrm{t}$} & \multirow{2}{*}{ Sig. } & \multicolumn{2}{|c|}{ B的 $95.0 \%$ 置信区间 } & \multicolumn{2}{|c|}{ 共线性统计量 } \\
\hline & & B & 标准误差 & & & & 下限 & 上限 & 容差 & VIF \\
\hline \multirow{4}{*}{1} & (常量) & 17.962 & 5.136 & & 3.497 & 001 & 7.695 & 28.229 & & \\
\hline & 八十年代员工个人价值观 & -.408 & 382 & -.105 & -1.069 & 289 & -1.172 & 356 & 900 & 1.112 \\
\hline & 硬汉型文化 & 764 & 325 & 335 & 2.350 & 022 & 114 & 1. 414 & 428 & 2. 337 \\
\hline & 奢注型文化 & 951 & 318 & 415 & 2.993 & 004 & 316 & 1.586 & 452 & 2.211 \\
\hline
\end{tabular}

a. 因变量: 绩效。

从表14和15中可以看出在八十年代员工价值观一企业 文化契合度与绩效回归分析中, $\mathrm{R}$ 方为 0.546 , 调整后的 $\mathrm{R}$ 方为 0.534 , 均大于 0.5 , 可以看出变量之间的线性关系较
强，样本数据的拟合优度较高; 回归的F值可以看出回归系 数 $0.000<0.001$, 则有显著性; DW为 1.931 接近于 2 , 则不存 在自相关; VIF值均小于 10 , 则也不存在多重线性问题。

表16 九十年代员工价值观一企业文化契合度与绩效回归分析结果。

\begin{tabular}{|c|c|c|c|c|c|c|c|c|c|c|}
\hline \multirow{2}{*}{ 模型 } & \multirow{2}{*}{$\mathrm{R}$} & \multirow{2}{*}{ R方 } & \multirow{2}{*}{ 调整R方 } & \multirow{2}{*}{ 标准估计的误差 } & \multicolumn{5}{|c|}{ 更改统计量 } & \multirow[b]{2}{*}{ Durbin-Watson } \\
\hline & & & & & R方更改 & F更改 & $\mathrm{df} 1$ & $\mathrm{df2}$ & Sig. F更改 & \\
\hline 1 & $696^{a}$ & 585 & 560 & 6.35292 & 485 & 19.445 & 3 & 62 & 000 & 2.038 \\
\hline
\end{tabular}

a. 预测变量: (常量), 享受型文化, 九十年代员工个人价值观, 奢注型文化。

b. 因变量: 绩效。

表17系数。

\begin{tabular}{|c|c|c|c|c|c|c|c|c|c|c|}
\hline \multirow{2}{*}{ 模型 } & & \multicolumn{2}{|c|}{ 非标准化系数 } & \multirow{2}{*}{$\begin{array}{l}\text { 标准系数 } \\
\text { 试用版 }\end{array}$} & \multirow[b]{2}{*}{$t$} & \multirow{2}{*}{ Sig. } & \multicolumn{2}{|c|}{ B的 $95.0 \%$ 置信区间 } & \multicolumn{2}{|c|}{ 共线性统计量 } \\
\hline & & $\mathrm{B}$ & 标准误差 & & & & $\begin{array}{l}\text { 下限 } \\
\end{array}$ & 上限 & 容差 & VIF \\
\hline \multirow{4}{*}{1} & （常量） & 16.214 & 5.572 & & 2.910 & 005 & 5.075 & 27.353 & & \\
\hline & 奢注型文化 & 696 & 400 & 304 & 1.739 & 087 & -. 104 & 1. 495 & 272 & 3. 670 \\
\hline & 九十年代员工个人价值观 & -.295 & 443 & -.068 & -.664 & 509 & -1.181 & 592 & 801 & 1. 248 \\
\hline & 享受型文化 & 1. 016 & 377 & 442 & 2.696 & 009 & 263 & 1.769 & 309 & 3. 236 \\
\hline
\end{tabular}

a. 因变量: 绩效。 
由上表可以看出在九十年代员工价值观一企业文化 契合度与绩效回归分析中, $R$ 方为 0.585 , 调整后的 $R$ 方为 0.560 , 均大于 0.5 , 可以看出变量之间的线性关系较强, 样本数据的拟合优度较高; 回归的F值可以看出回归系数 $0.000<0.001$, 则有显著性; DW为 2.038 接近于 2 , 则不存在 自相关; VIF值均小于 10 , 则也不存在多重线性问题。

\section{5. 结论}

对员工的管理是保证企业发展动力的源泉，也是企业 可持续发展的根本保障。员工所处的成长环境、教育环境 不同, 所形成的价值观也会有所不同。因此努力寻找员工 价值观与企业文化的共同点以及培养员工对企业文化的 认同感是促进员工以及企业绩效提高的关键。

\section{参考文献}

[1] 余世维. 企业文化与变革 [M]. 北京: 北京大学出版社, 2005。

[2] 丁政, 张光宇. 企业软实力结构模型的构建与解析 [J]. 科学 学与科技技术管理, 2007, 07：115-121。

[3] Schein, E. H. Organizational Cultureand Leadership. SecondEdition, San Francisco, CA: Jossey-Boss, 1992, $1-2$.

[4] 陈传明, 张敏. 企业文化的刚性特征: 分析与测度 [J]. 管理 世界，2005，06:101-106。
[5] HofstedeG, NeuijenB, OthayvDD, etal. Measuring Organizational Cultures; Aqualitative and Quantitative Studyacross Twenty Cases [J]. Administrative: Science Quarterly, 1990, Vol. $35: 286-316$.

[6] 秦海智, 蒋成程. 企业文化软实力与核心竞争力研究 $[J]$. 科技进步与对策，2013,07(30)。

[7] OfleillycA. Corporations, Cultureand Commitment: Motivationand Social Controlin Organizations [J]. California Management Rev. 1989. 3: 42-56.

［8］尹静. 基于个人价值观与企业文化契合度的企业文化落地 量化分析 $[\mathrm{J}]$. 中国人力资源开发, 2013 (13)。

[9] Seashore, S. E, Y. Ephraim. Factorial Analysis of Organizational Performance. Administrative Science Quarterly, 1967, 12(3): 377-395.

[10] Campbel1, J. P. On the Natural of Organizational Effectiveness. SanFrancisco: Jossey-Bass, 1977.

[11] 张玥, 张光旭. 90 后知识型员工工作价值观与离职倾向的关 系研究: 心理承受力的调节作用 $[\mathrm{J}]$. 中国市场, 2016 (22) 889。

[12］曲子鉴. 企业员工绩效管理与绩效改进一一以Y企业员工绩 效管理为例 [D]. 中国知网，2016.05。 